\title{
Dialysis Disequilibrium Syndrome: A Neurological Manifestation of Haemodialysis
}

\author{
Thomas Flannery \\ Queen's University Belfast/Belfast Health $\mathcal{E}$ Social Care Trust \\ Northern Ireland
}

\section{Introduction}

Renal insufficiency has many protean effects on the central nervous system. Early symptoms such as fatigue, clumsiness, and impaired concentration may progress to hallucinations, agitation, disorientation and coma if the renal insufficiency is untreated. The pathophysiology of these changes, due to uraemic encephalopathy are thought to be mediated by impaired neurotransmission (Burn \& Bates, 1998). Dialysis of patients with end-stage renal disease (ESRD) helps to minimize the effects of uraemic encephalopathy. However, dialysis of uraemic patients may in itself, also have deleterious effects on the nervous system. One of the potential neurologic sequelae of this treatment modality is dialysis disequilibrium syndrome. First described in 1962, the dialysis disequilibrium syndrome (DDS) is a central nervous system disorder that remains an important clinical problem in dialysis patients. It is characterized by neurologic symptoms of varying severity that are thought to be due primarily to cerebral oedema. Classically, DDS arises in individuals starting haemodialysis due to chronic renal failure and is associated, in particular, with "aggressive" (high solute removal) dialysis (Port et al., 1973).

\section{Incidence}

Dialysis disequilibrium syndrome has been reported most frequently after rapid haemodialysis and in certain high-risk groups (Arieff, 1989). However, this syndrome is likely to be under-reported given the often mild nature of DDS-type symptoms. First-time haemodialysis patients are at greatest risk, particularly if the blood urea nitrogen (BUN) levels are markedly elevated (above $175 \mathrm{mg} / \mathrm{dL}$ or $60 \mathrm{mmol} / \mathrm{L}$ ). In addition, patients with a sudden change in their dialysis regime, in particular, cases with increased dialysis flow rates are susceptible. Children and elderly patients may remain at increased risk, in particular those with a sudden change in their haemodialysis regime (Flannery et al, 2008). Patients with pre-existing neurologic disease, such as head injury, stroke or malignant hypertension, are also at greater risk for developing DDS (Peterson, 1964; Yoshida et al., 1987).

\section{Pathogenesis}

Although DDS has been recognized for more than forty years, the pathogenesis of DDS remains debated and incompletely understood. However, what is established and central to 
the diagnosis of DDS is a raised intracranial pressure. While many theories have been proposed, it is likely that the mechanism(s) underlying the intracranial hypertension are multifactorial.

\section{1 "The reverse urea effect"}

Haemodialysis rapidly removes small solutes such as urea, particularly in patients who have marked uraemia. Urea is generally considered an "ineffective" osmole, because of its ability to permeate cell membranes. However, this ability to cross the cell membrane may take several hours to reach completion. This "lag period" may be particularly relevant in the brain where the blood-brain barrier may contribute to a plasma-brain urea concentration gradient. As a result, urea transiently acts as an effective osmole, promoting water movement into the brain. In addition, the reduction in BUN lowers the plasma osmolality, thereby creating a transient osmotic gradient that promotes water movement into the cells. In the brain, this water shift across the blood-brain-barrier produces cerebral oedema and a variable degree of acute neurological dysfunction depending on the severity and speed of BUN reduction (Silver et al., 1996). The extracellular volume depletion associated with aggressive dialysis and consequent cerebral hypoperfusion may exacerbate the patient's clinical status. Absolute increases in brain water content have been demonstrated in a rat model of uraemia undergoing rapid haemodialysis that was accounted for by an increase in the ratio of brain to plasma urea (Silver et al., 1992; Silver, 1995). Downregulation of central nervous system urea transporters have also been proposed as a mechanism contributing to the delay in urea clearance from the brain, although there has been little additional evidence to confirm this theory (Hu et al., 2000).

\subsection{Intracerebral acidosis}

A number of reports suggest that the "reverse urea effect" cannot solely account for the development of cerebral oedema in DDS since urea movement out of the brain is sufficiently rapid to prevent a large osmotic gradient developing between the brain and extracellular fluid (Arieff et al, 1973). The rate of removal of urea from brain closely parallels its rate of removal from plasma, but the clearance of urea from the cerebrospinal fluid (CSF) is delayed (Arieff, 1989). Studies in dialysis patients have shown that there is often a substantial rise in the $\mathrm{P}_{\mathrm{CO} 2}$ of lumbar CSF, with a concomitant fall in its $\mathrm{pH}$ during haemodialysis (Arieff et al., 1973; Fraser \& Arieff, 1988). Studies in uraemic dogs treated with rapid haemodialysis have shown that, despite a rise in the $\mathrm{pH}$ of arterial blood, the $\mathrm{pH}$ of the CSF fell. It has been found in animal models that the decrement in the $\mathrm{pH}$ of the CSF is associated with a concomitant decline in the $\mathrm{pH}$ of the brain, and this finding is probably a factor in the pathogenesis of the DDS (Areiff et al., 1976). This decrease in cerebral intracellular $\mathrm{pH}$, resulting in the displacement of bound sodium and potassium by the excess hydrogen ions can increase intracellular osmolality and promote water movement into the brain.

An additional contributing factor to the intracerebral acidosis mechanism is the idiogenic osmole principle proposed by Arieff (1973). The increased osmolality of the extracellular fluid in uraemia may induce an adaptive accumulation of intracellular organic osmolytes to limit cerebral cell dehydration (Arieff et al., 1973). During haemodialysis, retention of these organic osmolytes contributes to a paradoxical reduction in intracellular $\mathrm{pH}$ resulting in increased brain osmolality and cerebral oedema (Arieff et al., 1976; Trachtman et al., 1993). 
These brain organic osmolytes may include glutamine, glutamate, taurine, and myoinositol. However, an increase in brain organic osmolytes has not been confirmed in all studies. A fall in the $\mathrm{pH}$ of CSF may contribute to a depression of the sensorium, and intracellular acidosis of brain cells could result in a rise of brain intracellular osmolality. Such an increase of osmolality could lead to cytotoxic oedema. The resulting cerebral oedema may be related to a decrease in intracellular $\mathrm{pH}$ of the cerbral cortex, probably as a consequence of an increase in intracellular organic acids.

\subsection{Dialysis disequilibrium syndrome-induced interstitial oedema}

The advent of magnetic resonance imaging (MRI), in particular diffusion-weighted imaging (DWI), has increased physicians' ability to evaluate brain water content. The apparent diffusion coefficient (ADC) measured by DWI, is sensitive in detecting dynamic changes in tissue water. This technique is useful in identifying neurological disorders where there is a derangement in the brain water dynamics e.g. stroke (Warach et al., 1995) and has recently been proposed as a useful investigation in patients with suspected DDS (Chen et al., 2007). In this study, the authors found that haemodialysis increased the ADC values of brain water, especially in white matter, indicating that interstitial oedema rather than cytotoxic oedema is more important in the pathogenesis of DDS-related brain oedema.

Foci of bright areas of white matter were found in all patients on T2-weighted images. The ADC values in white and gray matter in ESRD patients before and after haemodialysis, were significantly greater than those of the healthy controls $(p<0.005)$. Regarding the impact of haemodialysis, the ADC of frontal lobe white matter increased significantly after haemodialysis $(p=0.036)$. The authors concluded that because ADC is an indicator of interstitial as opposed to cytotoxic oedema, that DDS is a manifestation of an increase in interstitial fluid compartment, especially after first haemodialysis. Other contributing factors may include uraemic toxin-associated dysfunction of the blood-brain barrier in patients with ESRD before their first haemodialysis (Jeppsson et al., 1982). Hypertension is also prevalent in patients with ESRD at the initiation of long-term dialysis therapy, which may accelerate atherosclerosis and cause damage to cerebral vasculature in patients with ESRD, leading to the increase of the ADC (Goksan, et al., 2004).

\section{Evaluation of patients with suspected DDS}

Dialysis disequilibrium syndrome should be a diagnosis of exclusion in haemodialysis patients who develop new-onset neurological symptoms. Important differential diagnoses include uraemic encephalopathy, subdural haematoma, metabolic disturbances (hyponatraemia, hypoglycaemia), and drug-induced encephalopathy. Indeed, drug accumulation resulting in neurotoxicity may be a problem with drugs that are normally excreted by the kidney. Even in complex cases however, a detailed clinical evaluation coupled with relevant investigations will usually help to make the diagnosis of DDS.

\subsection{Symptoms and signs}

The classical DDS refers to acute symptoms developing during or immediately after haemodialysis. Early findings include headache, nausea, disorientation, restlessness, blurred vision, and asterixis. These and other vague symptoms such as muscle cramps, anorexia, and dizziness developing near the end of a dialysis treatment are also part of this syndrome. 
Papilloedema has also been reported to be associated with DDS and this can be a useful clinical sign in confirming the presence of raised intracranial pressure (Im et al., 2007). More severely affected patients may develop confusion, seizures, coma, and even death, although with greater awareness of DDS, these extreme cases are now very rare.

\subsection{Radiographic evaluation}

With the greater availability of computed tomography (CT) and magnetic resonance imaging (MRI) scanners, haemodialysis patients with new-onset neurological symptoms can readily undergo brain imaging to exclude a structural cause of their symptoms. Furthermore, with the technical advances in MR imaging, patients with suspected DDS can be imaged for brain water content using DWI sequences (Walters et al., 2001). As mentioned previously, an increase in ADC values have been reported in patients undergoing first-time haemodialysis in keeping with the associated increase in interstitial fluid water content (Chen et al., 2007). However, it is important to bear in mind that longstanding silent cerebral white matter lesions are present in up to one third of patients with chronic renal disease (Martinez-Vea et al., 2006). These lesions may be related to vascular risk factors, particularly hypertension, and reflect ischaemic brain damage caused by generalized vascular damage (Chen et al., 2007).

\subsection{Electroencephalography}

It appears that modern methods of dialysis have altered the clinical features of the DDS. Most of the seizures, coma and deaths related to DDS were reported before 1970, whereas the symptoms frequently reported since then are generally mild, consisting of headache, nausea, fatigue, weakness and muscle cramping ((Harris \& Townsend, 1989). As a consequence, although the use of electroencephalography (EEG) has decreased significantly in the investigation and monitoring of DDS patients, it may occasionally be required in the evaluation of some patients.

The EEG recording typically consists of bilateral bursts of high-voltage rhythmic delta waves and occasional spike and wave patterns on a high-voltage dysrhythmic background (Kennedy, 1970). In addition to the initial diagnostic applications, EEG has been used to monitor the effects of changing the dialysis fluid constituents (e.g. acetate versus bicarbonate). Neyer et al (1983) observed EEG changes more frequently in the acetate dialysis group compared with the bicarbonate group. Although values for serum urea, osmolarity and sodium was similar in both groups, correction in metabolic acidosis varied. After acetate haemodialysis, a negative base excess and fall in $\mathrm{PaCO} 2$ was observed while in the bicarbonate group, the $\mathrm{PaCO}_{2}$ rose and the base excess was positive. This report indicated the importance of the biochemical composition in haemodialysis fluid and in general, bicarbonate-based dialysate fluid has substituted acetate-based solutions. With the improvements in brain imaging, and less frequent severe cases of DDS, EEG has become less frequently used investigation for DDS-suspected cases.

\subsection{Intracranial pressure monitoring}

Although brain imaging has improved with more advanced MR sequences, the detection of DDS in patients with a coexistent disorder of the central nervous system can be problematic. In such cases DDS may be a contributing factor to the clinical features and may contribute to an elevation of intracranial pressure. In such cases, in particular neurosurgical patients (e.g. 
head trauma, intracranial haemorrhage, suspected shunt malfunction) intracranial pressure (ICP) monitoring can be a useful diagnostic and monitoring adjunct. The intracranial pressure of patients suspected of DDS, has been shown to rise almost immediately after the initiation of haemodialysis (Yoshida et al., 1987) and reach maximal values approximately two hours later (Fig. 1). Maximal recordings greater than $50 \mathrm{mmHg}$ are possible (Flannery et al., 2008) indicating that increased ICP during haemodialysis may be extreme and potentially harmful.

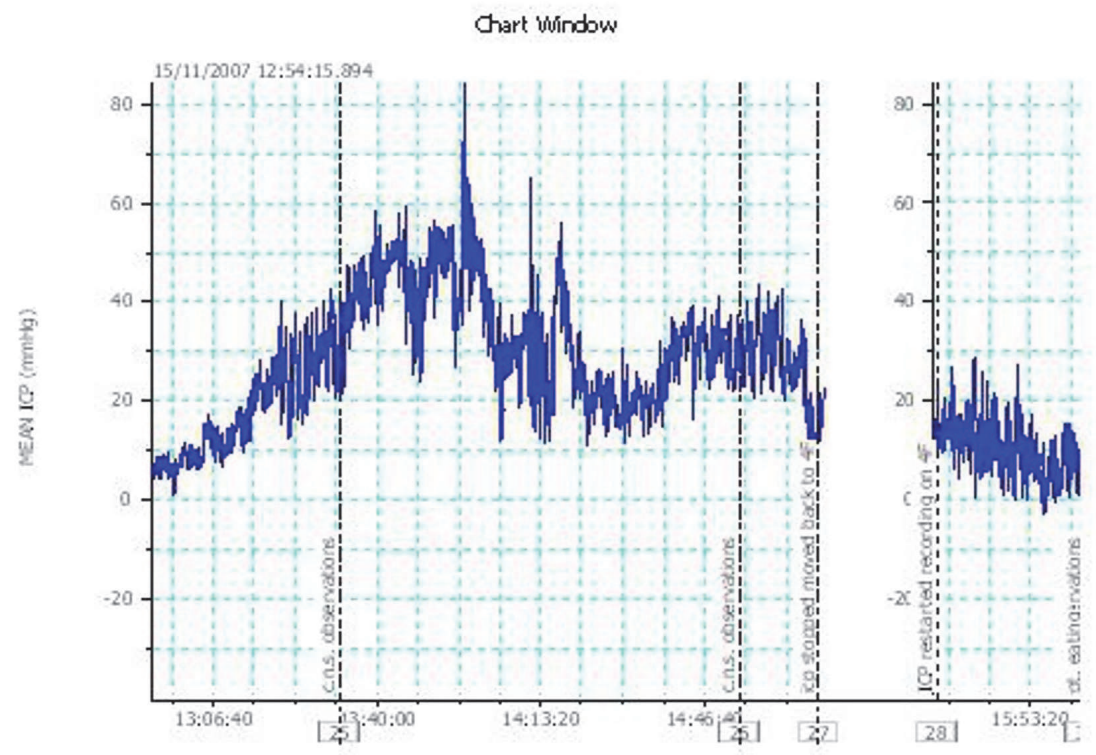

Fig. 1. A typical ICP recording obtained before, during, and at the end of Haemodialysis. (taken with permission from "Dialysis disequilibrium syndrome: a consideration in patients with hydrocephalus", Journal of Neurosurgery Paediatrics 2008; 2: 143-145).The ICP recording can be seen to rise shortly after commencement of dialysis (less than one hour) and return to normal fairly soon after dialysis was completed.

\section{Treatment of DDS}

The management of DDS can be categorized into preventive and therapeutic measures.

\subsection{Prevention of DDS}

Prevention is the mainstay of therapy in the DDS, particularly in first-time haemodialysis patients who are at greatest risk. Consequently, the mode of dialysis is important in reducing the likelihood of DDS. In general, DDS is seen less frequently with nonhaemodialysis modalities such as continuous ambulatory peritoneal dialysis (Bertrand et al., 1983; Dettori et al., 1982). Unfortunately, in some cases these alternative modes of dialysis may not be suitable e.g. peritoneal adhesions, patient intolerance, etc. Where haemodialysis is the only suitable option, a number of precautions can be taken to facilitate a gradual reduction in BUN and minimize the risk of DDS. These include intermittent haemodialysis 
using less efficient dialyzers with a smaller surface area and by reducing the duration and blood flow rate of dialysis (Bagshaw et al., 2004). It is also important to ensure that chronic dialysis patients do not undergo a sudden change in their dialysis regime perhaps implemented by a change in personal circumstances e.g. moving to a new dialysis unit (Flannery et al., 2008).

\subsection{Treatment of DDS symptoms}

Aside from measures to optimise dialysis parameters and minimizing the risk of DDS, the primary objective of DDS treatment is the reduction of raised intracranial pressure. Symptoms of DDS, in particular the milder symptoms, are generally self-limited and usually dissipate within several hours. However, the initial reports of DDS often contained cases of severe morbidity and even mortality. It is from these early reports that much of our knowledge of management of DDS symptoms arises (Port et al, 1973; Arieff et al, 1978; Harris \& Townsend, 1989).

Early studies indicated that DDS was successfully treated by the addition of either hyperosmotic or hyperoncotic solute (glucose, glycerol, albumin, urea, fructose, sodium chloride, mannitol) to the dialysate or by the substitution of sodium bicarbonate for sodium lactate (or acetate) in the dialysate (Port et al., 1973; Pagel et al., 1982; Rodrigo et al., 1977; Arieff et al., 1973; Fraser \& Arieff, 1988). The purpose of such manoeuvres was to minimize rapid alterations in the plasma osmolality or bicarbonate during dialysis. In uraemic animals undergoing rapid haemodialysis, the addition of glycerol or mannitol to the dialysate prevented many of the manifestations of experimental DDS. Studies on uraemic patients undergoing haemodialysis with glycerol or mannitol added to the dialysate suggest that these agents lessen the symptoms that may be associated with DDS. The substitution of bicarbonate for acetate or lactate in the dialysate appears to diminish cardiovascular instability and may prove useful in decreasing the symptoms of DDS in some patients (Arieff, 1989).

Intravenous mannitol may be given to elevate the plasma osmolality if ICP is increased and is a safe and effective clinical method for preventing ICP increase (Kennedy, 1970; Rodrigo et al., 1977). In the event of persistently elevated ICP in spite of medical measures, Yoshida et al report ventricular drainage as a relatively safe and effective surgical method of preventing irreversible brain herniation and death. The authors also proposed that a ventricular catheter allows for serial CSF sampling to monitor osmolality and urea concentration in complex cases to optimise dialysis parameters (Yoshida et al., 1987).

Although seizures are much less frequently observed compared with earlier reports, it may be necessary in some cases to administer prophylactic anti-epileptic medication to high-risk cases. A typical regimen might be a loading dose of $1000 \mathrm{mg}$ Phenytoin followed by $300 \mathrm{mg}$ daily until uraemia has been controlled. Severe DDS with seizures can also be rapidly reversed by raising the plasma osmolality with either hypertonic saline or mannitol. However, caution needs to be exercised in the selection of appropriate anti-epileptic medication as some are primarily excreted by the renal route.

\section{Other neurological sequelae of haemodialysis}

Dialysis disequilibrium syndrome is essentially a diagnosis of exclusion and dialysis patients presenting with neurological symptoms should be evaluated to exclude another pathological process. These disorders may require additional modes of treatment. 


\subsection{Subdural haematoma}

Subdural haematomas have been reported in 1.0 to $3.3 \%$ of patients undergoing haemodialysis. Contributory factors are coagulation problems associated with the uraemic state, and the use of anticoagulants for dialysis (Rashkin \& Fishman, 1976). There is often no preceding history of trauma. The clinical manifestations are variable and can resemble those of DDS. Up to $20 \%$ of subdural haematomas are bilateral and may cause gait disturbance predisposing patients to falls and head trauma. Cases with associated mass effect may require neurosurgical intervention following the reversal of anti-coagulant medication.

\subsection{Wernicke's encephalopathy}

Although thiamine is a water-soluble vitamin, and might be therefore expected to cross the dialysis membrane with ease, there have been only a few reports of Wernicke's encephalopathy in patients undergoing longterm dialysis (Burn \& Bates, 1998). The deficiency state is likely to develop due to a combination of factors including chronic malnourishment due to anorexia, a genetic predisposition and the use of glucose containing intravenous fluids. It should also be noted that classic features of Wernicke's encephalopathy e.g. opthalmoplegia, may be absent in dialysis patients (Jagadha et al., 1987).

\subsection{Dialysis dementia}

Dialysis dementia was first documented by Alfrey et al (1972), and typically the disorder is progressive unless treated. Dialysis dementia may be part of a multisystem disorder which includes vitamin D resistant osteomalacia, proximal myopathy, and iron deficient microcytic, hypochromic anaemia (Burn \& Bates, 1998). A mixed dysarthria and dysphasia with dysgraphia has been reported as one of the earliest signs of dialysis dementia in up to $95 \%$ of cases. The patient may initially have a stuttering, hesitant speech, which only occurs during and immediately after dialysis. Initially the patient may also be more apathetic and become depressed. As the disorder progresses, language function becomes more severely and persistently involved (Burn \& Bates, 1989).

Convulsions develop in up to $60 \%$ in the later stages, and psychosis with hallucinations and paranoid delusions may be prominent. Frank dementia becomes obvious in over $95 \%$ of patients with patients becoming immobile and mute in the preterminal stages (Chokroverty et al., 1976).

\section{Conclusions}

Although severe DDS is less common than initial reports due to improvements in modes of dialysis, milder forms of DDS may go unnoticed by the clinician. It is important to be aware of this diagnosis, particularly in high-risk groups, with the aim of prevention and early detection to limit the potentially more serious consequences of DDS.

\section{Acknowledgement}

The author is grateful to the editorial office of the Journal of Neurosurgery for permission to use Fig. 1. 


\section{References}

Alfrey, A.C., LeGendre, G.R., \& Kaehny, W.D. (1976). The dialysis encephalopathy syndrome: possible aluminium intoxication. N Eng J Med, Vol.294, No.4, (January 1976), pp. 184-188, ISSN 0028-4793

Arieff, A., Massry, S., Barrientos, A., \& Kleeman C. (1973). Brain water and electrolyte metabolism in uraemia: effects of slow and rapid haemodialysis. Kidney Internat, Vol.4, No.3, (September 1973), pp. 177-187, ISSN 0085-2538

Arieff, A., Guisado, R., Massry, S.G., \& Lazarowitz, V. (1976). Central nervous system pH in uraemia and the effects of haemodialysis. J Clin Invest, Vol.58, No.2, (August 1976), pp. 306-311, ISSN 0021-9738

Arieff, A.I, Lazarowitz, V.C., \& Guisado, R. (1978). Experimental dialysis disequilibrium syndrome: prevention with glycerol. Kidney Int, Vol.14, No.3, (September 1978), pp. 270-278, ISSN 0085-2538

Arieff, A.I. (1989). More on the Dialysis disequilibrium syndrome. Western J Med, Vol.151, No.1, (July 1989), pp. 74-76, ISSN 0093-0415

Arieff, A.I. (1994). Dialysis disequilibrium syndrome: current concepts on pathogenesis and prevention. Kidney Int, Vol.45, pp. 629-635, ISSN 0085-2538

Bagshaw, S.M., Peets, A.D., Hameed, M., Boiteau, P.J.E., Laupland, K.B., \& Doig, CJ. (2004). Dialysis disequilibrium syndrome: brain death following haemodialysis for metabolic acidosis and acute renal failure - a case report. BMC Nephrology, Vol.5, No.9, (August 2004), pp. 1-5, ISSN 1471-2369

Bertrand, Y.M., Hermant, A., Mahieu, P., \& Roels, J. (1983). Intracranial pressure changes in patients with head trauma during haemodialysis. Intensive Care Med, Vol.9, (November 1983), pp. 321-323, ISSN 0342-4642

Chen, C.L., Lai, P.H., Chou, K.J., Lee, P.T., Chung, H.M., \& Fang, H.C. (2007). A preliminary report of brain oedema in patients with uraemia at first haemodialysis: evaluation by diffusion-weighted imaging. Am J Neuroradiol Vol.28, No.1, (January 2007), pp. 68-71, ISSN 0195-6108

Chokroverty, S., Bruetman, M.E., Berger, V., \& Reyes, M.G. (1976). Progressive dialytic encephalopathy. J Neurol Neurosurg Psychiatry, Vol. 39, No. 5, (May 1976), pp. 411419, ISSN 1468-330X

Dettori, P., La Greca, G., Biasioli, S., Chiaramonte, S., Fabris, A., Feriani, M., Pinna, V., Pisani, E., \& Ronco, C. (1982). Changes of cerebral density in dialyzed patients. Neuroradiology, Vol.23, No.2, (April 1982), pp. 95-99, ISSN 0028-3940

Flannery, T., Shoakazemi, A., McLaughlin, B., Woodman, A., \& Cooke, S. (2008). Dialysis disequilibrium syndrome: a consideration in patients with hydrocephalus. J Neurosurg Paed, Vol.2, No.1, (August 2008), pp. 143-145, ISSN 1933-0707

Fraser, C.L., \& Arieff, A.I. (1988). Nervous system complications in uraemia. Ann Intern Med, Vol.109, No.2, (July 1988), pp. 143-153, ISSN 0003-4819

Goksan, B., Karaali-Savrun, F., Ertan, S., \& Savrun, M. (2004). Haemodialysis-related headache. Cephalgia, Vol.24, No.4, (April 2004), pp. 284-287, ISSN 1468-2982

Harris, C.P. \& Townsend, J.J. (1989). Dialysis disequilibrium syndrome [Clinicopathologic Conference]. West J Med, Vol.151, No.1, (July 1989), 52-55, ISSN 0093-0415

$\mathrm{Hu}$, M.C., Bankir, L., Michelet, S., Rousselet, G., \& Trinh-Trang-Tan, M.M. (2000). Massive reduction of urea transporters in remnant kidney and brain in uraemic rats. Kidney Internat, Vol.58, No.3, (September 2000), pp. 1202-1210, ISSN 0085-2538 
Im, L., Atabay, C., \& Eller, A.W. (2007). Papilloedema associated with dialysis disequilibrium syndrome. Semin Opthalmol, Vol.22, No.3, (July-September 2007), 133-135, ISSN 0882-0538

Jagadha, V., Deck, J.H., Halliday, W.C., \& Smyth, H.S. (1987). Wernicke's encephalopathy in patients on peritoneal dialysis or haemodialysis. Ann Neurol, Vol.21, No.1, (January 1987), pp. 78-84, ISSN 0364-5134

Jeppsson, B., Freund, H.R., Gimmon, Z., James, J.H., von Meyenfeldt, M.F., \& Fischer, J.E. (1982). Blood-brain barrier derangement in uraemic encephalopathy. Surgery, Vol.92, No.1, (July 1982), pp. 30-35, ISSN 0039-6060

Kennedy, A.C. (1970). Dialysis Disequilibrium syndrome. Electroencephalogr Clin Neurophysiol, Vol.29, No.2, (August 1970), pp. 206-219, ISSN 0013-4694

Martinez-Vea, A., Salvado, E., Bardaji, A., Gutierrez, C., Ramos, A., Garcia, C., Compete, T., Peralta, C., Broch, M., Pastor, R., Angelet, P., Marcas, L., Sauri, A., \& Oliver, J.A. (2006). Silent cerebral white matter lesions and their relationship with vascular risk factors in middle-aged predialysis patients with CKD. Am J Kidney Dis, Vol.47, No.2, (February 2006), pp. 241-250, ISSN 0272-6386

Neyer, U., Woss, E., Haller, R., \& Kross, R. (1983). Headache and EEG changes caused by acetate and bicarbonate dialysis. Acta Med Austriaca, Vol.10, No.1, (January 1983), pp. 15-23, ISSN 1563-2571

Pagel, M.D., Ahmad, S., Vizzo, J.E., \& Scribner, B.H.. (1982). Acetate and bicarbonate fluctuations and acetate intolerance during dialysis. Kidney Int, Vol.21, No.3, (March 1982), pp. 513-518, ISSN 0085-2538

Peterson, H., \& Swanson, A.G. (1964). Acute encephalopathy occurring during haemodialysis. The reverse urea effect. Arch Intern Med, Vol.113, (June 1964), pp. 877-880, ISSN 0003-9926

Port, F.K., Johnson, W.J., \& Klass, D.W. (1973). Prevention of dialysis disequilibrium syndrome by use of high sodium concentration in the dialysate. Kidney Int, Vol.3, No.5, (May 1973), pp. 327-333, ISSN 0085-2538

Rashkin, N.H., \& Fishman, R.A. (1976). Neurologic disorders in renal failure (Part II). N Engl J Med, Vol.294, No.4, (January 1976), pp. 204-210, ISSN 0028-4793

Rodrigo, F., Shideman, J., McHugh, R., Buselmeier, T., \& Kjellstrand, C. (1977). Osmolality changes during haemodialysis. Natural history, clinical correlations, and influence of dialysate glucose and intravenous mannitol. Ann Intern Med, Vol.86, No.5, (May 1977), pp. 554-561, ISSN 0003-4819

Silver, S.M., DeSimone, J.A. Jr., Smith, D.A., \& Sterns, R.H. (1992). Dialysis disequilibrium syndrome (DDS) in the rat: role of the "reverse urea effect". Kidney Internat, Vol.42, No.1, (July 1992), pp. 161-166, ISSN 0085-2538

Silver, S.M. (1995). Cerebral oedema after rapid dialysis is not caused by an increase in brain organic osmolytes. J Am Soc Nephrol, Vol.6, No.6, (December 1995), pp. 1600-1606, ISSN 1046-6673

Silver, S.M., Stearns, R.H., \& Halperin, M.L. (1996). Brain swelling after dialysis: old urea or new osmoles? Am J Kidney Dis, Vol.28, No.1, (July 1996), pp. 1-13, ISSN 0272-6386

Trachtmann, H., Futterweit, S., Tonidanel, W., \& Gullans, S. (1993). The role of organic osmolytes in the cerebral cell volume regulatory response to acute and chronic renal failure. J Am Soc Nephrol, Vol.3, No.12, (June 1993), pp. 1913-1919, ISSN 10466673 
Walters R., Fox N., Crum W., Taube D., \& Thomas D. (2001). Haemodialysis and cerebral oedema. Nephron, Vol.87, No.2, (February 2001), pp. 143-147, ISSN 0028-2766

Warach, S., Gaa, J., Siewert, B., Wielopolski, P., \& Edelman, P.R. (1995). Acute human stroke studied by whole brain echo planar diffusion-weighted magnetic resonance imaging. Ann Neurol, Vol.37, No.2, (February 1995), pp. 231-241, ISSN 0364-5134

Yoshida, S., Tajika, T., Yamasaki, N., Tanikawa, T., Kitamura, K., Kudo, K., Lyden, P. (1987). Dialysis dysequilibrium syndrome in neurosurgical patients. Neurosurgery, Vol.20, No.5, (May 1987), pp. 716-721, ISSN 0148-396X 


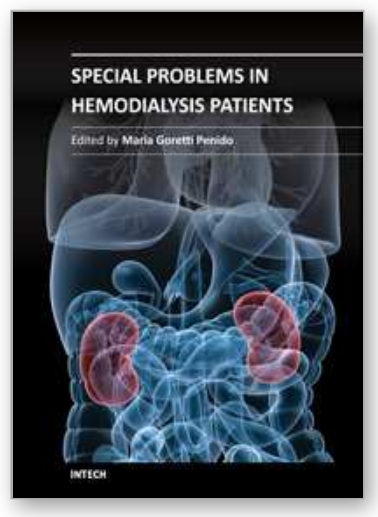

\author{
Special Problems in Hemodialysis Patients \\ Edited by Prof. Maria Goretti Penido
}

ISBN 978-953-307-396-5

Hard cover, 192 pages

Publisher InTech

Published online 14, November, 2011

Published in print edition November, 2011

This book provides an overview of special cases in hemodialysis patients. Authors have contributed their most interesting findings in dealing with patients suffering of other diseases simultaneously, such as diabetes, cardiovascular disease and other health problems. Each chapter has been thoroughly revised and updated so the readers are acquainted with the latest data and observations in these complex cases, where several aspects are to be considered. The book is comprehensive and not limited to a partial discussion of hemodialysis. To accomplish this we are pleased to have been able to summarize state of the art knowledge in each chapter of the book.

\title{
How to reference
}

In order to correctly reference this scholarly work, feel free to copy and paste the following:

Thomas Flannery (2011). Dialysis Disequilibrium Syndrome: A Neurological Manifestation of Haemodialysis, Special Problems in Hemodialysis Patients, Prof. Maria Goretti Penido (Ed.), ISBN: 978-953-307-396-5, InTech, Available from: http://www.intechopen.com/books/special-problems-in-hemodialysis-patients/dialysisdisequilibrium-syndrome-a-neurological-manifestation-of-haemodialysis

\section{INTECH}

open science | open minds

\section{InTech Europe}

University Campus STeP Ri

Slavka Krautzeka 83/A

51000 Rijeka, Croatia

Phone: +385 (51) 770447

Fax: +385 (51) 686166

www.intechopen.com

\section{InTech China}

Unit 405, Office Block, Hotel Equatorial Shanghai

No.65, Yan An Road (West), Shanghai, 200040, China

中国上海市延安西路65号上海国际贵都大饭店办公楼405单元

Phone: +86-21-62489820

Fax: +86-21-62489821 
(C) 2011 The Author(s). Licensee IntechOpen. This is an open access article distributed under the terms of the Creative Commons Attribution 3.0 License, which permits unrestricted use, distribution, and reproduction in any medium, provided the original work is properly cited. 